\title{
Using a 1-D model to reproduce the diurnal variability of SST
}

\author{
Karagali, Ioanna; Høyer, Jacob L.; Donlon, Craig J.
}

Published in:

Journal of Geophysical Research: Oceans

Link to article, DOI:

10.1002/2016JC012542

Publication date:

2017

Document Version

Publisher's PDF, also known as Version of record

Link back to DTU Orbit

Citation (APA):

Karagali, I., Høyer, J. L., \& Donlon, C. J. (2017). Using a 1-D model to reproduce the diurnal variability of SST. Journal of Geophysical Research: Oceans, 122(4), 2945-2959. https://doi.org/10.1002/2016JC012542

\section{General rights}

Copyright and moral rights for the publications made accessible in the public portal are retained by the authors and/or other copyright owners and it is a condition of accessing publications that users recognise and abide by the legal requirements associated with these rights.

- Users may download and print one copy of any publication from the public portal for the purpose of private study or research.

- You may not further distribute the material or use it for any profit-making activity or commercial gain

- You may freely distribute the URL identifying the publication in the public portal

If you believe that this document breaches copyright please contact us providing details, and we will remove access to the work immediately and investigate your claim. 


\section{Journal of Geophysical Research: Oceans}

\section{RESEARCH ARTICLE}

10.1002/2016JC012542

Key Points:

- Oceanic water temperature is simulated using a one-dimensional turbulence model

- In situ measured and ECMWF forcing fields are used as initial conditions

- The model reproduces well-observed temperature and its diurnal variability

Correspondence to:

I. Karagali,

ioka@dtu.dk

Citation:

Karagali, I., J. L. Høyer, and C. J. Donlon (2017), Using a 1-D model to reproduce the diurnal variability of SST, J. Geophys. Res. Oceans, 122, 29452959, doi:10.1002/2016JC012542.

Received 10 NOV 2016 Accepted 7 MAR 2017 Accepted article online 11 MAR 2017 Published online 8 APR 2017

\section{Using a 1-D model to reproduce the diurnal variability of SST}

\author{
loanna Karagali1 (D), Jacob L. Høyer², and Craig J. Donlon³ \\ ${ }^{1}$ Department of Wind Energy, Technical University of Denmark, Risø Campus, Roskilde, Denmark, ${ }^{2}$ Climate and Arctic \\ Research, Danish Meteorological Institute, Copenhagen, Denmark, ${ }^{3}$ ESA-ESTEC, Noordjwiik, The Netherlands
}

\begin{abstract}
A wide range of applications, from air-sea interaction studies to fisheries and biological modeling, need accurate, high resolution SST which requires that the diurnal signal is known; for many applications, diurnal estimates are necessary and should be included in blended SST products. A widely preferred approach to bridge the gap between in situ and remotely sensed measurements and obtain diurnal warming estimates at large spatial scales is modeling of the upper ocean temperature. This study uses the onedimensional General Ocean Turbulence Model (GOTM) to resolve diurnal signals identified from satellite SSTs and in situ measurements. Focus is given on testing and validation of different parameterizations of the basic physical processes known to influence the generation of a warm surface layer. GOTM is tested and validated using in situ measurements obtained at three locations, two in the Atlantic Ocean and one in the Baltic Sea, where different oceanographic and atmospheric conditions occur, in order to obtain an insight into its general performance. It is found that the model, with a 9 band solar absorption model rather than the standard 2 band scheme, performs well when using 3 hourly NWP forcing fields and is able to resolve daily SST variability seen both from satellite and in situ measurements. As such, and due to its low computational cost, it is proposed as a candidate model for diurnal variability estimates.
\end{abstract}

\section{Introduction}

The diurnal variability of SST has been extensively studied as it poses challenges for validating and calibrating satellite retrievals and merging SST time series due to the different time sampling that leads to different measured temperatures. Modeling of the ocean-atmosphere system also requires accurate SST, as a boundary condition. The diurnal signal's maximum amplitude is best captured by radiometers since heat is significantly trapped close to the ocean surface. Hourly infrared SST retrievals allow monitoring of the diurnal cycle. Nonetheless, validation of satellite SST against in situ measurements reveals differences associated with the different reference depths. Within the scientific community, research on modeling the daily SST variability is undertaken to aid ocean and atmospheric modeling as well as climate SST time series [e.g., Embury et al., 2012; Merchant et al., 2014].

The use of a computationally simple model, able to reproduce the diurnal variability of SST, has applications for removing diurnal signals from day-time satellite SST retrievals and for ocean-atmosphere and climate modeling, as most oceanic and atmospheric models use a daily, or even weekly SST field. Such an assumption may result in errors of the surface fluxes [Webster et al., 1996; Zeng and Dickinson, 1998; Ward, 2006; Clayson and Bogdanoff, 2013; Marullo et al., 2016]; the importance of including the diurnal variability of SST in atmospheric and oceanic models has been demonstrated by Bernie et al. [2007, 2008]. Bernie et al. [2005] used a one-dimensional vertical mixing model and observed fluxes from a mooring in the western Pacific to show the impact of the diurnal SST cycle on the intraseasonal variability of daily mean SST and its importance for the coupling of the surface and deeper ocean. Bernie et al. [2007] used a standard configuration of an ocean global circulation model, i.e., without a diurnally varying SST, to demonstrate the impact of diurnal variability on the intraseasonal SST variability and the representation of the Ekman spiral through the current variability. They also showed the importance of including the diurnal variability in reanalysis products.

Models for the diurnal SST variability can be generally separated in three categories, i.e., simple parameterizations, bulk and turbulence, or diffusion models. Parameterizations use wind and downward short-wave radiation to predict the maximum amplitude of the diurnal cycle. They are computationally efficient and simple to use but, as most have been developed using observational evidence and some form of regression
(C) 2017. American Geophysical Union. All Rights Reserved. 
analysis [Webster et al., 1996; Gentemann et al., 2003; Clayson and Weitlich, 2007], they are tuned to local conditions. Stuart-Menteth et al. [2005] developed a parameterization for the diurnal SST variability based on wind and downward short-wave radiation, allowing for the variation of the signal's phase, which was found to perform very well for the $1 \mathrm{~m}$ and subskin layers compared to observations at different locations. Filipiak et al. [2012] model uses a statistical approach by fitting diurnal warming observations from the geostationary infrared radiometer SEVIRI to wind and insolation from a numerical weather prediction (NWP) system.

Bulk models represent the mixed layer and distribute surface heat and momentum fluxes over its depth by assuming a constant profile along the water column. While they are more physically based than the parameterizations, they do not include some dynamical processes that contribute to air-sea interaction, e.g., wave breaking. One of the most used models, described in Fairall et al. [1996a], is a simplified version of an older approach pioneered by Price et al. [1986]. Zeng and Beljaars [2005] developed a similar model which was introduced in the ECMWF NWP chain with positive impact. Their model along with two more parameterizations were compared with 1 year of hourly SSTs from SEVIRI in the North Sea/Baltic Sea region by Karagali and Høyer [2013], reporting large discrepancies. Takaya et al. [2010] developed a modified version of the Zeng and Beljaars [2005] model, with improved stability function and reduced the very large amplitudes of diurnal warming, which were also reported in Karagali and Høyer [2013]. Schiller and Godfrey [2005] implemented a parameterization for the diurnal SST variability in a one-dimensional ocean mixed-layer model, obtaining a more realistic representation of SST. A sensitivity of the mixed-layer depth and diurnal SST cycle on the attenuation length's parameterization was reported, with the various Jerlov water types [Jerlov, 1968] producing differences up to $0.5^{\circ} \mathrm{C}$. The Profiles of Ocean Surface Heating (POSH) model [Gentemann et al., 2009] was developed as an improvement to the Fairall et al. [1996a] model, using in situ measurements of surface temperature and its vertical distribution.

Turbulence closure models solve the equations for the distribution of heat, momentum, and salt across the water column. Such models are physically more realistic but computationally costly. Kantha and Clayson [1994] developed a modified second moment closure mixed layer model that showed good skill in reproducing SST variability. The General Ocean Turbulence Model (GOTM) [Burchard et al., 1999] has been successfully used in Hallsworth [2005]; Pimentel et al. [2008a,2008b] showing the ability to reproduce the diurnal variability with a very high computational efficiency, which can be considered its advantage over other turbulence closure models.

Most of the previous studies using turbulence models were performed for a small variety of regions and often only in one location. This has limited the possibility to assess the general performance of the model under different oceanic and atmospheric conditions. The present study uses measurements from three different locations, not used previously. Two locations are in the Tropical and North Atlantic Ocean and one in the Baltic Sea; the diurnal variability in these three regions was demonstrated in Karagali and Høyer [2014] to be distinctly different regarding frequency of diurnal warming events, mean shape and amplitude of the cycle. Testing the model performance in different conditions gives a valuable insight into the general performance of GOTM. Additionally, this study investigates the sensitivity of different GOTM setups and their impact on the model's performance.

The aim is to use GOTM for modeling of the SST diurnal signal at different depths thus bridging the gap between different types of measured and retrieved SST. The scientific community is focusing on high quality SST products with increased spatial and temporal resolution for physical studies, atmospheric, biological, oceanic as well as climate modeling. The temporal resolution of SST is significantly improved with the use of multisensor observations, especially as the number of satellites increases. Nonetheless, overpass times render SST retrievals subject to diurnal variability thus making the composition of reanalysis products challenging. Moreover, gaps in the global, high resolution SST coverage occur due to the thermal infrared SST retrievals, which are obscured by clouds. Modeling of the daily SST variability is fundamental to overcome such issues as diurnal warming estimates from an accurate and computationally efficient model can be included in operational, blended SST products and improve the air-sea heat fluxes in oceanic and atmospheric models.

All in situ, remotely sensed and model data used in this study are presented in section 2. GOTM is briefly described in section 3. Sensitivity tests regarding the internal GOTM parameters and the forcing fields are 


\section{QAGU Journal of Geophysical Research: Oceans}
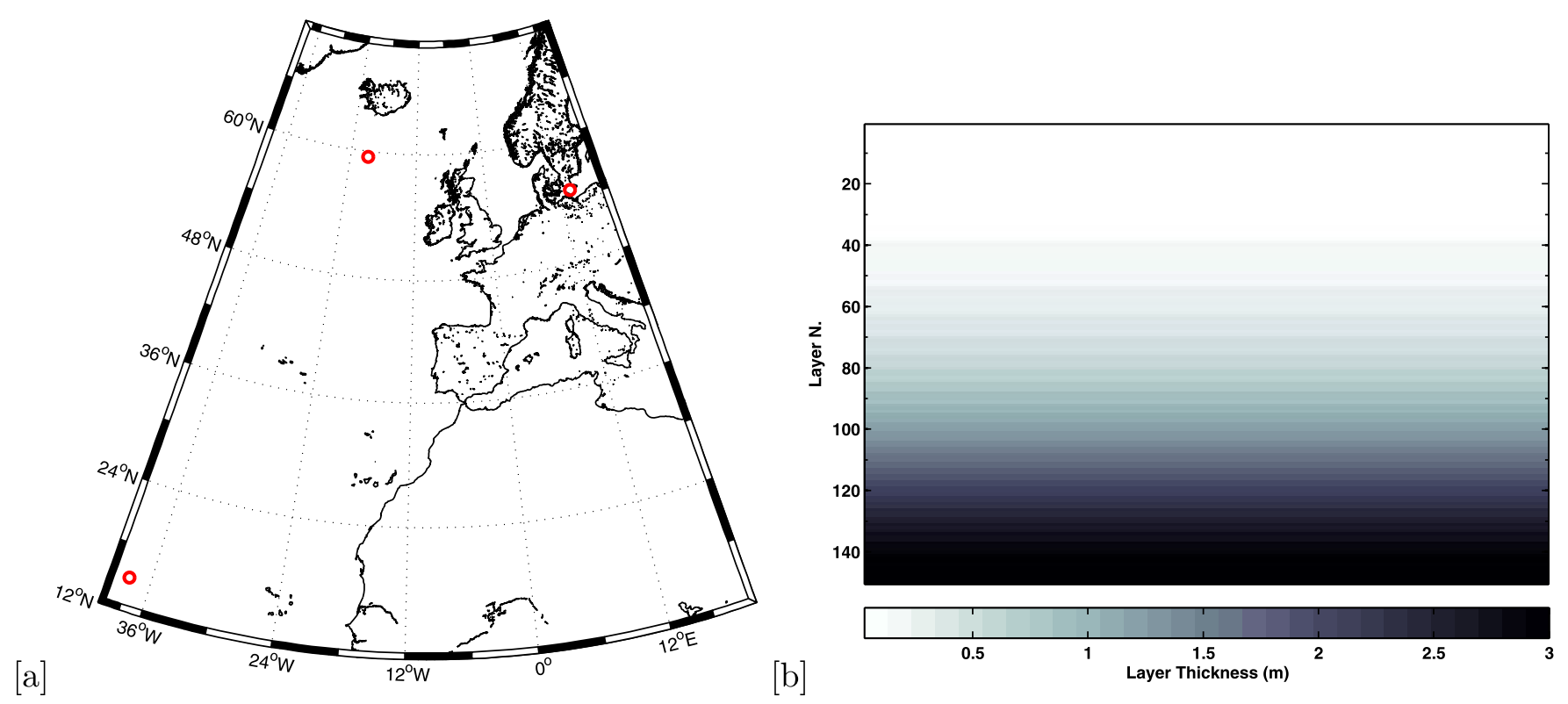

Figure 1. (a) The three sites with measured oceanographic and meteorological variables used for the GOTM setup. (b) GOTM layer thickness.

presented in section 4 while results using some selected setups are shown in section 5 . Finally, discussion of the results and key conclusions are summarized in section 6.

\section{Data}

The locations of the three mooring sites from which data are used in this study are shown in Figure $1 \mathrm{a}$.

\subsection{MLML91}

The Marine Light-Mixed Layer 1991 (MLML91) experiment occurred from 29 April to 6 September 1991. The mooring's position was $59.489^{\circ} \mathrm{N}, 20.826^{\circ} \mathrm{W}$ where the water depth was $2822 \mathrm{~m}$. Instruments measured east and north wind components, air temperature, barometric pressure, relative humidity, incident long-wave, and short-wave radiation at the height of $3 \mathrm{~m}$, every $15 \mathrm{~min}$. Water temperature at depths of 2, 10, 30, 50, $70,80,102,118$, and $150 \mathrm{~m}$ were observed every $15 \mathrm{~min}$ [Plueddemann et al., 1995]. Data are maintained by the Upper Ocean Processes Group of the Woods Hole Oceanographic Institute.

\subsection{PIRATA}

The Prediction and Researched Moored Array in the Atlantic (PIRATA) network mooring located at $15^{\circ} \mathrm{N}$, $38^{\circ} \mathrm{W}$, where the water depth is $\sim 4000 \mathrm{~m}$, was chosen due to the additional availability of long-wave radiation measurements. It is equipped with temperature sensors, the upper most of which are at 1, 5, 10, 13, 20, $40,60,80,100,120$, and $140 \mathrm{~m}$ measuring every $10 \mathrm{~min}$. Observations of wind speed and direction, air temperature, and relative humidity at $4 \mathrm{~m}$ were obtained every $10 \mathrm{~min}$, air pressure at $3 \mathrm{~m}$ height was recorded hourly, while measurements of downwelling short-wave and long-wave radiation at $3.5 \mathrm{~m}$ height were observed every $2 \mathrm{~min}$. Data are obtained from the Tropical Atmosphere Ocean (TAO)/TRITON project, for the period 2006-2007, when long-wave radiation was available.

\subsection{Arkona Becken}

The Bundesamt für Seeschifffahrt und Hydrographie (BSH) Institute maintains the Arkona platform, located in the Baltic Sea $\left(54.88^{\circ} \mathrm{N}, 13.87^{\circ} \mathrm{E}\right)$, where the water depth is $45 \mathrm{~m}$. Temperature sensors are placed at 2, 5, $7,16,25,33,40,43$, and $45 \mathrm{~m}$ depth, obtaining hourly measurements. Observations of wind speed and direction, air pressure and temperature, relative humidity, and downwelling short-wave radiation are obtained hourly at a height of $10 \mathrm{~m}$. The period April to September 2013, used in this study, was the first year that short-wave radiation was measured at the station. 


\subsection{SEVIRI}

Subskin SST [Donlon at al., 2010] from the Spinning Enhanced Visible/Infrared Imager (SEVIRI) on the geostationary Meteosat Second Generation (MSG), centered at $0^{\circ} \mathrm{N}, \mathrm{E}$, was obtained from the Ocean \& Sea Ice Satellite Application Facility (O\&SI SAF) through IFREMER/CERSAT for 2013. The subskin SST is obtained during the retrieval as the original observations refer to skin SST. The product is hourly, gridded at a $0.05^{\circ}$ regular grid [Ocean \& Sea Ice SAF, 2013] and has been extensively used for observing and characterizing diurnal variability [e.g., Merchant et al., 2008; Karagali et al., 2012; Karagali and Høyer, 2014].

\subsection{ECMWF}

The $10 \mathrm{~m} \mathrm{U}$-wind and V-wind components, surface pressure, $2 \mathrm{~m}$ air and dew point temperature, fractional cloud cover, downwelling surface solar radiation and surface net solar radiation were extracted from the European Centre for Medium-Range Weather Forecasts (ECMWF) Atmospheric Model Operational Archive version 1, through the Meteorological Archival and Retrieval System (MARS) for time periods corresponding to the availability of in situ observations from the three different locations. The fields are 3 hourly and on a $0.125^{\circ}$ latitude/longitude grid.

\subsection{Temperature Profiles}

Monthly climatological temperature profiles from the objectively analyzed World Ocean Atlas 2013 (WOA13) were obtained from the National Oceanic and Atmospheric Administration's (NOAA) National Oceanographic Data Center (NODC) [Locarnini et al., 2013]. Temperature values are on $0.25^{\circ}$ grid, with a resolution of $5 \mathrm{~m}$ from 0 to $100 \mathrm{~m}$ and of $25 \mathrm{~m}$ from 100 to $500 \mathrm{~m}$. The EN4.0.2 objective analysis monthly ocean temperature profiles from the UK Meteorological Office Hadley Centre [Good et al., 2013] are on a $1^{\circ}$ grid, with a vertical resolution of approximately $10-11 \mathrm{~m}$ from 5 to $110 \mathrm{~m}$, and continue to $5350 \mathrm{~m}$ with decreasing vertical resolution. The Baltic Sea Physics Analysis data set, from a three-dimensional hydrodynamical model of the Danish Meteorological Institute (DMI), is available through the MyOcean project (http://www.myocean.eu/). Hourly modeled temperature is available with a $5 \mathrm{~m}$ resolution between 0 and $100 \mathrm{~m}$ and with a spatial resolution of $1.9 \mathrm{~km}$.

\section{Model Description}

GOTM solves the one-dimensional equations for the transport of heat, momentum, and salt allowing for different options for the description of turbulence quantities [Burchard et al., 1999]. A 9-band parameterization for the absorption of solar radiation in the water column [Paulson and Simpson, 1981] is implemented along with a new parameterization for the downwelling long-wave radiation [Grant and Hignett, 1998]. New stability methods, describing the diffusivity of heat and momentum (Table 1), were also added. The first-order K $\epsilon$ turbulence scheme [Burchard and Baumert, 1995] is used in agreement with Hallsworth [2005] and Pimentel et al. [2008a].

Surface heat and momentum fluxes can be directly prescribed or calculated from surface meteorological variables using the bulk algorithm of Fairall et al. [1996a,1996b] incorporating the skin and warm layer adjustments. Downwelling short-wave and long-wave radiation can be either prescribed or calculated, independent of the remaining surface fluxes. For the short-wave radiation calculation, the time, location, and cloud cover information are required. When using in situ measurements as forcing fields for GOTM, only incoming short-wave radiation measurements are available and therefore, calculating the short-wave radiation is expected to be less accurate than prescribing it, due to the lack of in situ cloud cover information.

The vertical grid in GOTM is calculated according to equation (1) as in Pimentel [2007]

$$
h(i)=D * \frac{\tanh \frac{i}{D / 3}-\tanh \frac{i-1}{D / 3}}{\tanh 3}
$$

where $i$ is the layer number, $h$ is the layer height, and $D$ is the depth of the water column. The layer thickness is shown in Figure 1b, with approximately 65 layers in the top $10 \mathrm{~m}$. In the case of shallower bathymetry, the vertical grid is adjusted to the physical conditions. The model time step is $1 \mathrm{~min}$ and temperature values are saved every hour. All times are using the format of the forcing fields and are therefore UTC. 


\begin{tabular}{|c|c|c|}
\hline Category & \multicolumn{2}{|c|}{ Option } \\
\hline \multicolumn{3}{|c|}{ I. Surface fluxes } \\
\hline & 1 & Prescribed (usually from NWP outputs) \\
\hline & 2 & Calculated using meteorological inputs \\
\hline \multicolumn{3}{|c|}{ II. Short-wave radiation } \\
\hline & 1 & Prescribed (usually from NWP outputs) \\
\hline & 2 & Calculated (using meteorological inputs) \\
\hline \multicolumn{3}{|c|}{ III. Long-wave radiation (BRM) } \\
\hline & 1 & Clark et al. [1974] \\
\hline & 2 & Hastenrath and Lamb [1978] \\
\hline & 3 & Bignami et al. [1995] \\
\hline & 4 & Berliand and Berliand [1952] \\
\hline & 5 & $\begin{array}{l}\text { Brunt formula, coefficients } \\
\text { Grant and Hignett [1998] }\end{array}$ \\
\hline \multicolumn{3}{|c|}{ IV. Length scale method } \\
\hline & 1 & Dynamic dissipation \\
\hline & 2 & Mellor-Yamada $q^{2} I$ \\
\hline & 3 & Generic Length Scale \\
\hline \multicolumn{3}{|c|}{ V. Stability method } \\
\hline & 1 & Mellor-Yamada \\
\hline & 2 & Burchard and Baumert [1995], full version \\
\hline & 3 & Kantha and Clayson [1994], quasiequilibrium \\
\hline \multicolumn{3}{|c|}{ VI. Light extinction } \\
\hline \multirow[t]{5}{*}{2 bands } & 1 & Jerlov-I [Jerlov, 1968] \\
\hline & 2 & Jerlov-I (for upper $50 \mathrm{~m}$ ) \\
\hline & 3 & Jerlov-IA \\
\hline & 4 & Jerlov-IB \\
\hline & 5 & Jerlov-II \\
\hline \multirow[t]{3}{*}{9 bands } & 6 & Paulson and Simpson [1981] \\
\hline & 7 & Paulson and Simpson [1981], COART \\
\hline & 8 & Paulson and Simpson [1981], MODTRAN \\
\hline
\end{tabular}
of measuring all relevant meteorological observations such as wind, pressure, humidity, and air temperature. The 15 min observations of SWR prescribed in GOTM were internaly time-interpolated to the model time step and stored every $1 \mathrm{~h}$; they also show the correct variability.

The impact of the stability method was evaluated (Table 1, V) when calculating the surface fluxes and prescribing SWR. For the period 6-10 June at MLML91, the $2 \mathrm{~m}$ model temperature was compared to the observed. The lowest GOTM minus buoy temperature difference $(\mu=0)$ and standard deviation $\left(\sigma=0.15^{\circ} \mathrm{C}\right)$ along with the highest correlation ( $r=0.82$ ) was obtained using the Kantha and Clayson [1994] quasiequilibrium version (V.3). Figure 2a shows statistics of GOTM minus buoy temperatures, modeled using different options for the length scale and light extinction methods. Numbers on the $x$ axis refer to the combination of options and the three grouped bars represent the mean bias $\mu$ between GOTM and the buoy temperature, the standard deviation $\sigma$ and correlation coefficient $r$. Highest $\mu$ is obtained for the second length scale method. Overall lowest $\mu$ is achieved when using the generic length scale method, also proposed in Umlauf and Burchard [2003], and the 9-band parameterization for the light extinction; using the dynamic dissipation equation results in similar $\mu$ and lower $\sigma$. Such similar results between options 1 and 3 for the length scale were identified in other locations, not shown here, while the second option showed some cases of computational instabilities.

A diurnal warming event of more than $1.5^{\circ} \mathrm{C}$ was identified from the $1 \mathrm{~m}$ buoy temperature at PIRATA, during 22-25 August 2006. In situ measured meteorological variables and downwelling SWR were used to initialize GOTM, while different settings for the downwelling long-wave radiation (BRM) and light extinction methods were tested. Results are summarized in Figure $2 \mathrm{~b}$, where the $x$ axis indicates the combination of options for the long-wave radiation and the light extinction. A general trend of increasing $\mu$ for the different options of the 2-band light extinction model is identified, followed by a decrease for the 9-band model while $\sigma$ shows little variation. Many combinations result in almost zero $\mu$ and there is a very small variation of $\sigma$ and $r$ amongst the different setups.

Errors in the in situ measured forcing fields can lead to discrepancies between the measured and modeled absolute temperature. For diurnal warming estimates, the amplitude of the cycle is also of interest thus the 


\section{QAGU Journal of Geophysical Research: Oceans}
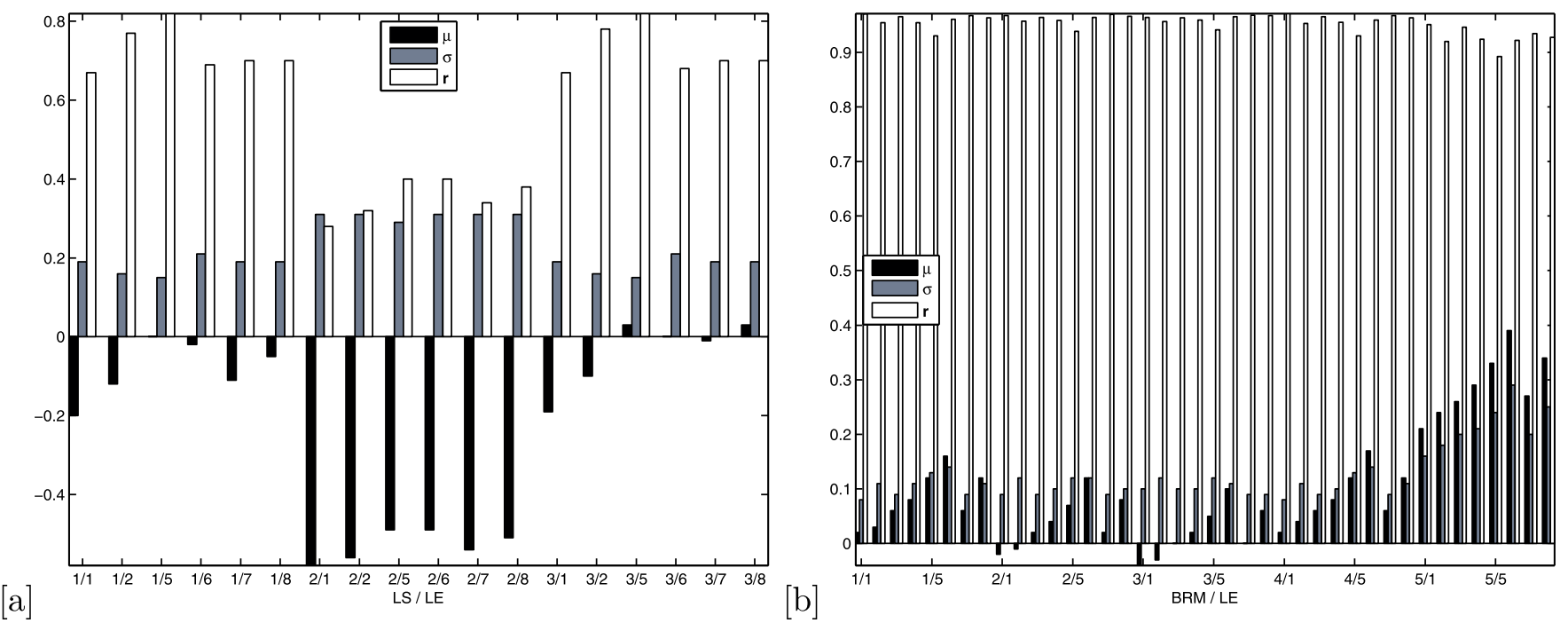

Figure 2. (a) Statistics for the $2 \mathrm{~m}$ GOTM-MLML temperature, with option 3 for the stability, $1-3$ for the length scale and 1, 2, 5, 6, 7, 8 for the light extinction. (b) Statistics for the $1 \mathrm{~m}$

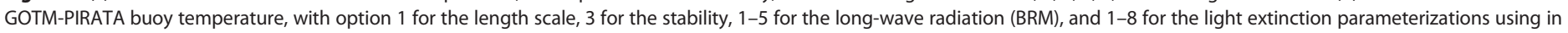
situ meteorological measurements and one temperature profile.

diurnal variability was estimated at the Arkona Becken location. The mean temperature from midnight to 04:00 at the depth of $5 \mathrm{~m}$ was defined as the foundation temperature, i.e., the temperature assuming wellmixed conditions [Donlon at al., 2010], and was computed for each individual day. The foundation temperature for each day was then subtracted from the hourly $2 \mathrm{~m}$ temperature to estimate the diurnal variability, both for the measured and modeled temperature. The $5 \mathrm{~m}$ sensor was selected to ensure that no diurnal signal would be included in the foundation temperature, as it could happen for the $2 \mathrm{~m}$ sensor (see Figure $6 \mathrm{c}$ ). This choice was further supported by reported mean differences between SEVIRI foundation fields and the 2, 5, and $7 \mathrm{~m}$ temperatures at Arkona Becken of $<0.2 \mathrm{~K}$ [Karagali et al., 2012].

The statistics of the GOTM minus in situ estimated diurnal variability from April to September 2013 at Arkona Becken (not shown) indicated biases lower than $0.1^{\circ}$ and $\sigma$ lower than $0.4^{\circ}$ with the SWR calculated, despite the lack of accurate cloud cover information. All methods for the long-wave radiation resulted in similar statistics as well as the light extinction parameterizations; option VI.7 resulted in the lowest $\mu$ and $\sigma$ and highest $r$.

From sensitivity tests performed, including those at MLML and the existing literature, the choice of some parameters from Table 1 was considered conclusive, e.g., for the stability and length scale methods. For others, such as the light extinction parameterization, sensitivity tests are performed in other locations since the absorption of light depends on water properties that vary with location.

\subsection{Forcing Fields}

ECMWF meteorological variables and climatological and modeled temperature profiles were used to examine the impact of the forcing fields. Figure 3 shows the statistics of modeled minus measured temperature at PIRATA, during 22-25 August 2006. ECMWF forcing with the SWR prescribed and in situ temperature profiles (Figure 3a) resulted in some biases becoming slightly negative but no impact on $\sigma$ and $r$ was identified. With the climatological profiles biases mostly became negative and $\sigma$ increased slightly; the UKMO profile (Figure $3 \mathrm{~b}$ ) resulted in smaller $\mu$ compared to the WOA one (not shown).

A comparison between the buoy measured and ECMWF meteorological variables and SWR for the PIRATA location during 22-25 August 2006, is shown in Figure 4(left). The top 2 plots show the hourly $10 \mathrm{~m} \mathrm{U}$-wind and V-wind components for the in situ measurements and 3 hourly for ECMWF. The middle plot shows the surface air pressure, while the bottom plots show the air temperature at $10 \mathrm{~m}$ for the measurements and $2 \mathrm{~m}$ for ECMWF and surface solar irradiance, correspondingly. While the variability seen from the hourly in situ measurements cannot be captured by the 3 hourly ECMWF fields, a reasonable agreement is found for the U-wind and V-wind components and SWR. Cases of discrepancies in the wind components at low wind 


\section{QAGU Journal of Geophysical Research: Oceans}
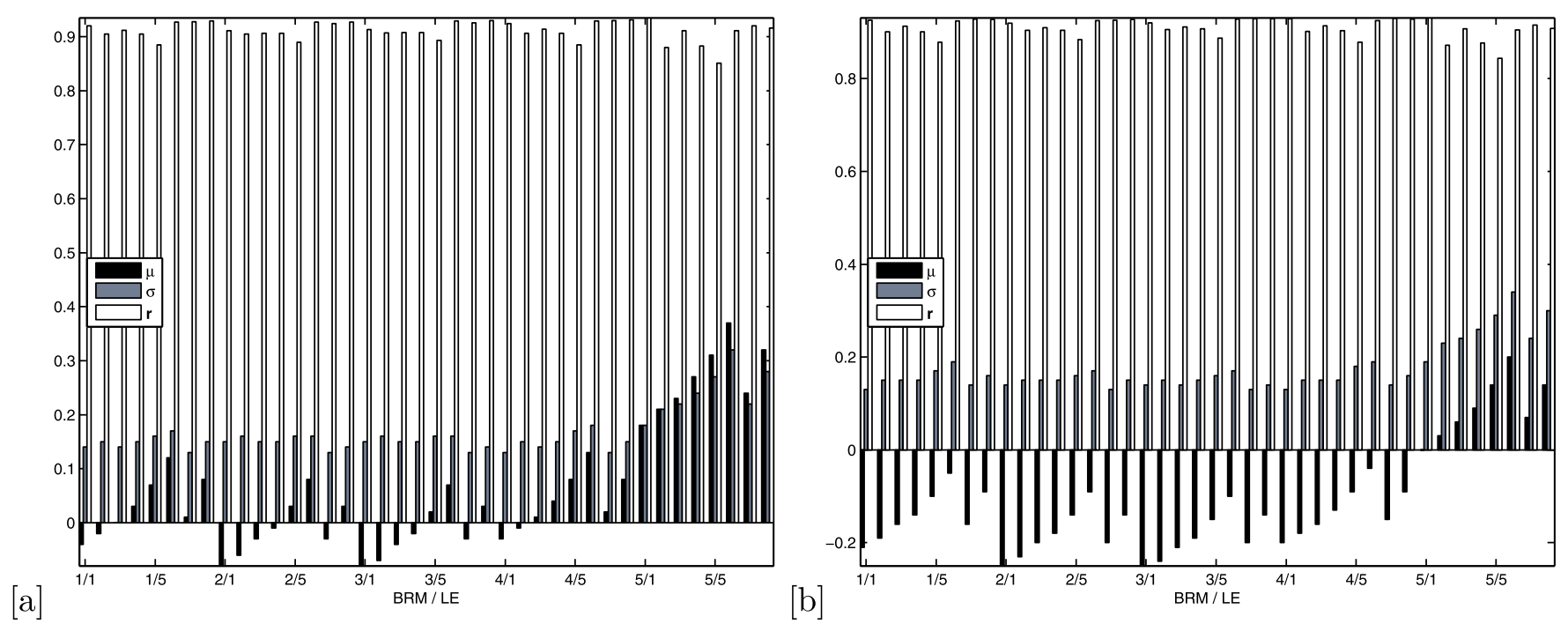

Figure 3. Statistics for the $1 \mathrm{~m}$ GOTM-PIRATA temperature during 22-25 August 2006, using option 1 for the length scale (IV), 3 for the stability (V), $1-5$ for the long-wave radiation (III), and 1-8 for the light extinction (VI) parameterizations. (a) ECMWF meteorological variables and in situ temperature profile and (b) ECMWF and UKMO.

regimes are identified with ECMWF being lower than the buoy measurements, thus intensifying the chances for modeled diurnal warming. The ECMWF pressure field is higher especially for the first 2 days while a disagreement in the air temperature is also identified for the same period. Given such differences in the forcing fields, differences in the modeled temperature are to be expected.

A similar comparison at the Arkona Becken, during 10 days in July 2013, is shown in Figure 4(right). The plots show the same variables as for the PIRATA location described previously. Some small deviations between the measurements and ECMWF are evident for the air temperature and the solar irradiance, with the in situ values being generally higher than ECMWF. Such differences between in situ measurements and mesoscale model outputs are to be expected if one considers that models cannot resolve the small scale features and are rather representative of conditions at larger scales. Nonetheless, the agreement is better than that at PIRATA.

Table 2 summarizes the statistics between the modeled and observed $2 \mathrm{~m}$ temperature during 10 days at Arkona Becken, using in situ and model forcing. Statistics between the GOTM $1.5 \mathrm{~cm}$ temperature and SEVIRI are also shown for comparison. The first option for the long-wave radiation (III.1) and the seventh for the
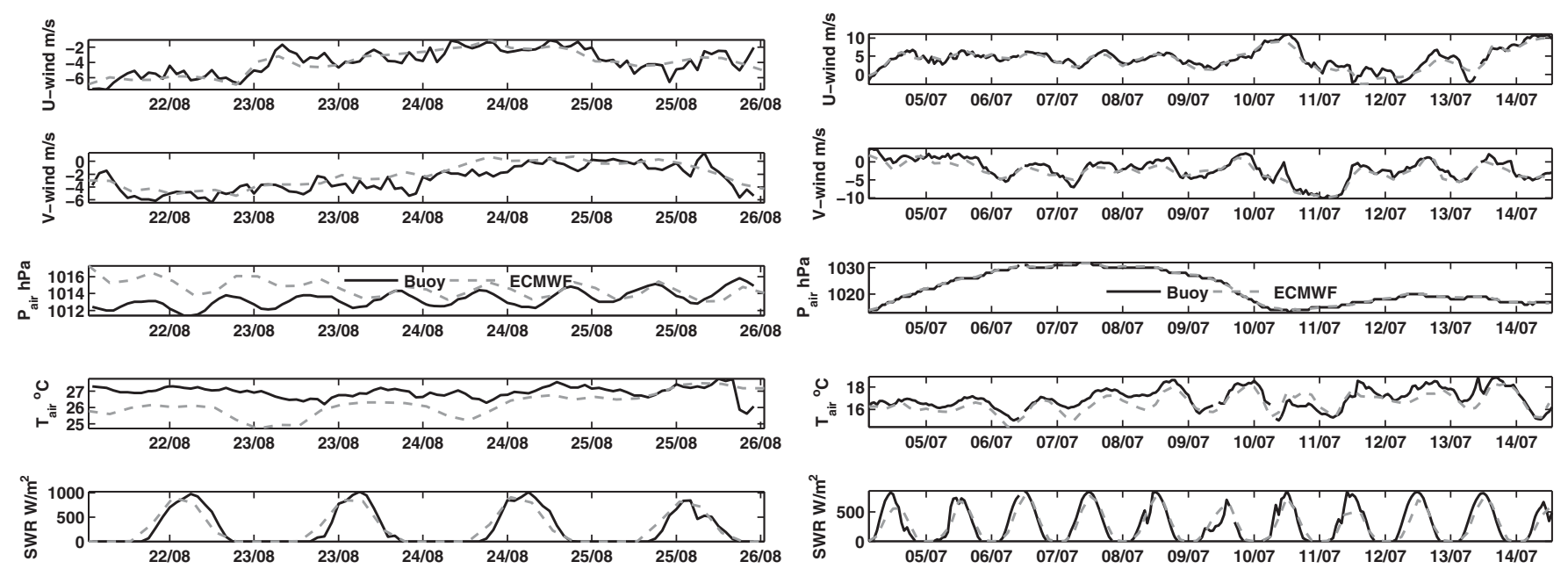

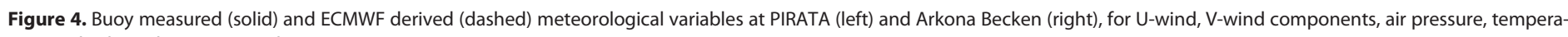
ture, and solar radiation (top to bottom). 
Table 2. Mean Bias $\mu$, Standard Deviation $\sigma$, Root Mean Square Error (RMSE) and Correlation Coefficient $r$ for GOTM-Buoy Temperatures at Arkona Becken (4-14 July 2013) and GOTM-SEVIRI (9-14 July 2013)

\begin{tabular}{|c|c|c|c|c|c|c|c|c|c|c|c|}
\hline & & \multicolumn{2}{|c|}{ IS } & \multicolumn{2}{|c|}{ ECMWF, $T_{\text {IS }}$} & \multicolumn{2}{|c|}{ ECMWF,T UкMO } & \multicolumn{2}{|c|}{ ECMWF, $T_{W O A}$} & \multicolumn{2}{|c|}{ ECMWF, $T_{\mathrm{DMI}}$} \\
\hline & & II.1 & 11.2 & II.1 & 11.2 & II.1 & 11.2 & II.1 & II.2 & II.1 & 11.2 \\
\hline \multirow[t]{4}{*}{ Buoy } & $\mu$ & -2.80 & -0.21 & -0.65 & -1.32 & -0.34 & -0.91 & -0.24 & -0.79 & -0.58 & -0.67 \\
\hline & $\sigma$ & 0.42 & 0.15 & 0.18 & 0.15 & 0.16 & 0.17 & 0.16 & 0.18 & 0.18 & 0.19 \\
\hline & RMSE & 2.83 & 0.26 & 0.68 & 1.33 & 0.38 & 0.92 & 0.29 & 0.81 & 0.60 & 0.69 \\
\hline & $r$ & 0.96 & 0.97 & 0.97 & 0.97 & 0.97 & 0.97 & 0.96 & 0.96 & 0.96 & 0.96 \\
\hline \multirow[t]{4}{*}{ SEVIRI } & $\mu$ & -1.85 & -0.20 & -0.36 & -1.35 & -0.17 & -1.03 & 0.09 & -0.94 & -0.31 & -0.83 \\
\hline & $\sigma$ & 0.72 & 0.23 & 0.63 & 0.24 & 0.55 & 0.24 & 0.54 & 0.25 & 0.59 & 0.27 \\
\hline & RMSE & 1.99 & 0.30 & 0.72 & 1.37 & 0.57 & 1.06 & 0.54 & 0.97 & 0.67 & 0.88 \\
\hline & $r$ & 0.88 & 0.93 & 0.80 & 0.93 & 0.78 & 0.94 & 0.77 & 0.93 & 0.79 & 0.90 \\
\hline
\end{tabular}

light extinction (VI.7) are used for all GOTM runs. The first column shows statistics derived using in situ measured forcing fields and prescribing (II.1) or calculating SWR (II.2). The large bias between modeled and measured temperatures for the prescribed SWR is explained if errors in the measured SWR are assumed. This is further justified by the bias reduction $(-0.21 \mathrm{~K})$ and low $\sigma(0.15 \mathrm{~K})$ when SWR is calculated from the measured meteorological variables. Biases are larger for the calculated SWR when ECMWF forcing is used, without exceeding $0.2 \mathrm{~K}, \sigma$ remains below $0.2 \mathrm{~K}$ and $r$ is 0.96 or higher. This can be associated with the higher uncertainty of the NWP cloud cover field. GOTM minus SEVIRI root mean square errors (RMSE) are also lower when in situ forcing is used and SWR is calculated. ECMWF fields result in lower GOTM minus SEVIRI RMS errors with SWR directly prescribed compared to calculated; these errors are marginally higher than the ones of the GOTM minus buoy comparison.

\section{Reproducing Diurnal Warming Events}

Using setups that resulted in good agreement between GOTM and observations at some depth, the top layer GOTM temperatures are compared to satellite subskin SSTs from SEVIRI. The aim is to evaluate if a given GOTM setup can represent temperatures at the surface as well as at some depth, thus providing the link between satellite and in situ observations. Figure 5a shows selected model configurations and the 15 min MLML91 $2 \mathrm{~m}$ buoy temperature (black solid line). Some options are the same for all GOTM configurations (III.1—due to the good statistics in another location, IV.1 and V.3) while others vary. Using the in situ forcing $(\mathrm{I} .2$, II.1) with option 5 for the light extinction (black dashed line) shows the correct daily variability but overestimates the second day's peak amplitude. This can be attributed to a mismatch between the measured surface meteorological variables and the measured water temperature. ECMWF forcing with SWR calculated (common independent of initial profiles), the in situ temperature profile and option 8 for the light extinction (gray solid) resulted in modeled temperature with overestimated peak values, especially when the larger warming events occurred. The temperature difference of $0.8 \mathrm{~K}$ between the morning minimum and daytime maximum, as measured from the buoy during the first and last day, is reproduced when forcing GOTM with the in situ forcing and it is underestimated by $\sim 0.2 \mathrm{~K}$ using ECMWF. Using the UKMO profile with option 7 for the light extinction (gray dashed) and the WOA13 profile with option 1 (gray circles) results in a shift of the temperature to higher values. This is associated with the higher temperature of the climatological profiles compared to the measurements. The statistics of GOTM-MLML91 temperatures are shown in Table 3. The in situ temperature profile results in the lowest $\mu$, $\sigma$ does not change by more than $0.05^{\circ} \mathrm{C}$ for the different forcing fields while $r$ is highest when the in situ forcing is used, with the second highest $r$ occurring for the ECMWF forcing and WOA13 profile combination.

Figure 5b summarizes selected setups for PIRATA. GOTM forced with all the in situ measured variables (black dashed) reproduces remarkably the $1 \mathrm{~m}$ temperature variability at the buoy (black solid), slightly overestimating the peak temperature the first 2 days but capturing the maximum of the large event on the third day. ECMWF forcing fields with the in situ temperature profile (gray solid) result in a better representation of the peak warming during the first day, but the peak event of the third day is slightly underestimated $\left(<0.2^{\circ} \mathrm{C}\right)$. The warming and cooling phases are accurately resolved, with a slight overestimation of the morning minimum temperature. The UKMO (gray dashed) and WOA (gray diamonds) profiles result in lower temperatures, persistent during the first day. This underestimation is compensated for at the second day when 


\section{QAGU Journal of Geophysical Research: Oceans}
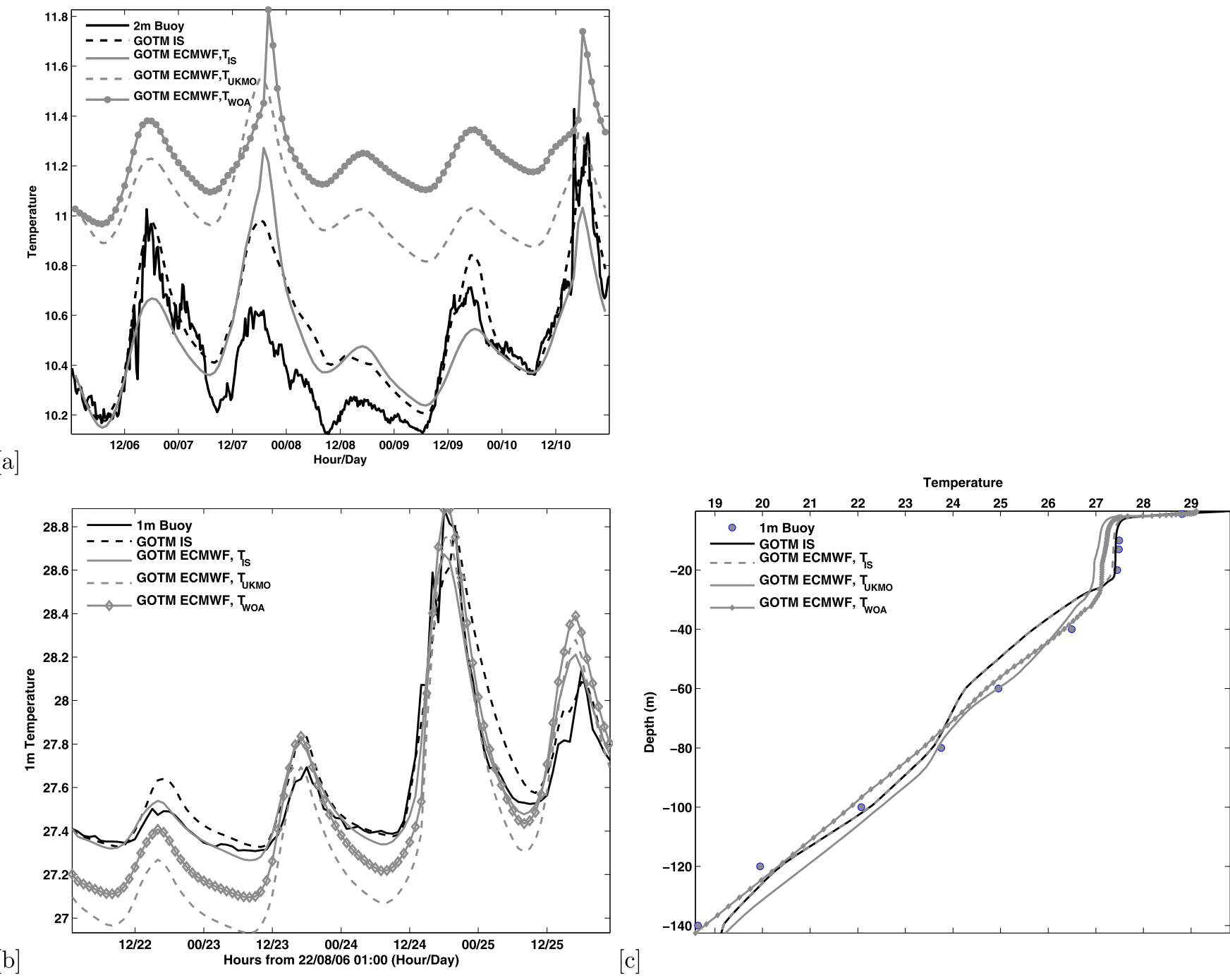

Figure 5. (a) 2 m temperature from MLML (solid black), GOTM with in situ measured forcing fields and short-wave radiation (black dashed) and ECMWF forcing fields with the shortwave radiation calculated and in situ temperature profiles (gray solid), UKMO profiles (gray dashed) and WOA13 profiles (gray circles). (b) $1 \mathrm{~m}$ temperature from PIRATA (solid black), GOTM using in situ measured forcing fields (black dashed) and or ECMWF forcing fields and in situ temperature profiles (gray solid), UKMO profiles (gray dashed) and WOA13 profiles (squares). (c) Temperature profiles from PIRATA (circles) and different GOTM runs for the peak day-time temperature on 24 August 2006.

the peak temperature is properly resolved (UKMO) or slightly overestimated (WOA). The peak of the third day is also accurately resolved, despite the lower minimum temperatures of the previous night. All GOTM runs used option III. 1 for the long-wave radiation parameterization and the 9-band model for the light extinction, even though the latter did not always result in the lowest $\mu$, as seen from Figure $2 c$. A discussion

\begin{tabular}{|c|c|c|c|c|c|}
\hline & & IS & ECMWF, $T_{\text {IS }}$ & ECMWF,T UKMO & ECMWF, T \\
\hline \multirow[t]{4}{*}{ MLML (2 m) } & $\mu$ & 0.00 & 0.05 & 0.59 & 0.78 \\
\hline & $\sigma$ & 0.15 & 0.19 & 0.20 & 0.17 \\
\hline & RMSE & 0.15 & 0.20 & 0.62 & 0.80 \\
\hline & $r$ & 0.82 & 0.66 & 0.58 & 0.71 \\
\hline \multirow[t]{4}{*}{ PIRATA (1 m) } & $\mu$ & 0.06 & 0.01 & -0.19 & -0.05 \\
\hline & $\sigma$ & 0.11 & 0.13 & 0.20 & 0.19 \\
\hline & RMSE & 0.13 & 0.13 & 0.27 & 0.20 \\
\hline & $r$ & 0.95 & 0.93 & 0.92 & 0.92 \\
\hline
\end{tabular}

${ }^{\mathrm{a}}$ The combinations of forcing fields and temperature profiles used are as in Figure 5. 
related to the 9-band model follows later. The statistics between GOTM and the buoy temperature are available in Table 3. The absolute $\mu$ exceeds $0.1^{\circ} \mathrm{C}$ only when the UKMO profile is used, while $r$ is high for all combinations. Using the in situ temperature profile results in lower $\sigma$, increasing by no more than $0.1^{\circ} \mathrm{C}$ when using the climatological profiles.

Figure $5 \mathrm{c}$ shows the measured and modeled PIRATA buoy vertical temperature structure at the time of peak warming on 24 August 2006 with the start of the model run on 22 August 2006 as shown previously. A very good agreement between the buoy and GOTM using the in situ profile is identified down to $23 \mathrm{~m}$. The UKMO and WOA profiles result in $0.5^{\circ}$ cooler temperatures down to approximately $30 \mathrm{~m}$, with almost no vertical temperature variability; a feature also seen in the measured profile. Below $30 \mathrm{~m}$, in the thermocline, GOTM using the WOA profile (gray squares) simulates the measured temperatures more accurately compared to using the in situ profile (black and gray solid), but the maximum difference does not exceed $1^{\circ} \mathrm{C}$. Other than the forcing fields and temperature profiles, the choice of light extinction parameterization also varies. While always using the 9-band model, runs initialized with the in situ profile use both attenuation lengths and proportional coefficients from Paulson and Simpson [1981]; runs initialized with the WOA and UKMO profiles use proportional coefficients from the Coupled Ocean and Atmosphere Radiative Transfer (COART) model [Jin et al., 2006]. The different proportional coefficients can explain this deviation of the profiles from the measurements, as will be discussed later on.

Figure $6 a$ shows the diurnal variability, i.e. the difference between the $2 \mathrm{~m}$ and foundation temperature, as observed from measurements at Arkona Becken (black solid) and modeled with GOTM (black dashed) using the in situ forcing fields and the settings I.2-II.2-III.1-IV.1-V.8-VI.7. A time period of 9 days is modeled, with daily temperature anomalies up to $1^{\circ} \mathrm{C}$. GOTM captures the variability observed at the buoy, resolving most daily maximum and minimum values. The maximum of the first day and the minimum of the sixth day are underestimated by approximately $0.2^{\circ} \mathrm{C}$. When ECMWF forcing fields (gray) and different temperature profiles are used, the day-to-day variability is very well represented and the amplitudes well captured. An underestimation of the peak variability on July 4 and an overestimation on the July 9 is also observed. Using temperature profiles other than the in situ (gray solid) generally results in slightly lower day-time maximum and night-time cooling minimum values, but without exceeding $0.1^{\circ} \mathrm{C}$. Such discrepancies are more obvious for the WOA and UKMO profiles compared to the DMI profile.

Figure $6 \mathrm{~b}$ shows the GOTM top layer temperature at approximately $1.5 \mathrm{~cm}$ (solid) and the SEVIRI SSTs for 914 July, at the Arkona Becken location. The agreement between the modeled and satellite-derived SST, when available, is notable considering that the two are completely independent and the diurnal variability seen in SEVIRI SST is well captured by GOTM. The peak event occurring on the fourth day (July 12) is very well resolved using the in situ forcing fields while being overestimated by $1.2^{\circ} \mathrm{C}$ when ECMWF forcing is used. Different temperature profiles result in some amplitude variability, in the order of $0.3^{\circ}$, during the cooling phases and minima of the cycle rather than the peaks. This is mostly evident for the UKMO and WOA profiles which tend to drive a larger temperature deviation from the in situ profile (gray solid) compared to the DMI profile (gray dotted). Figure $6 \mathrm{c}$ shows that the vertical structure of temperature in the upper $20 \mathrm{~m}$ is well captured and GOTM, using one initial temperature profile, successfully links the temperature observed from the in situ instrumentation (circles) and SEVIRI (square). The deviation between the observations and GOTM below $25 \mathrm{~m}$ at the Arkona Becken location can be attributed to complex inflow of high salinity bottom water from the North Sea [Sellschopp et al., 2006], which is not resolved by the model. Such discrepancies at greater depths were not observed at the PIRATA buoy.

\section{Discussion and Conclusions}

As diurnal variability of the upper ocean temperature is important for understanding the climate system [e.g., Clayson and Bogdanoff, 2013], efforts for observing and modeling the daily cycle of SST are ongoing. Ocean, atmospheric, and climate models, that approximate air-sea interaction processes, often use as boundary conditions SST L4 products. These are derived by blending SST retrievals from different sensors that represent surface temperature at different times of the day. Thus, the diurnal variability poses a significant challenge when trying to create stable and accurate SST time series representative of the upper ocean temperature. In this context, the GOTM model was used with the purpose of reproducing upper ocean temperatures at three different locations, characteristic of different environments where diurnal warming has 


\section{QAGU Journal of Geophysical Research: Oceans}
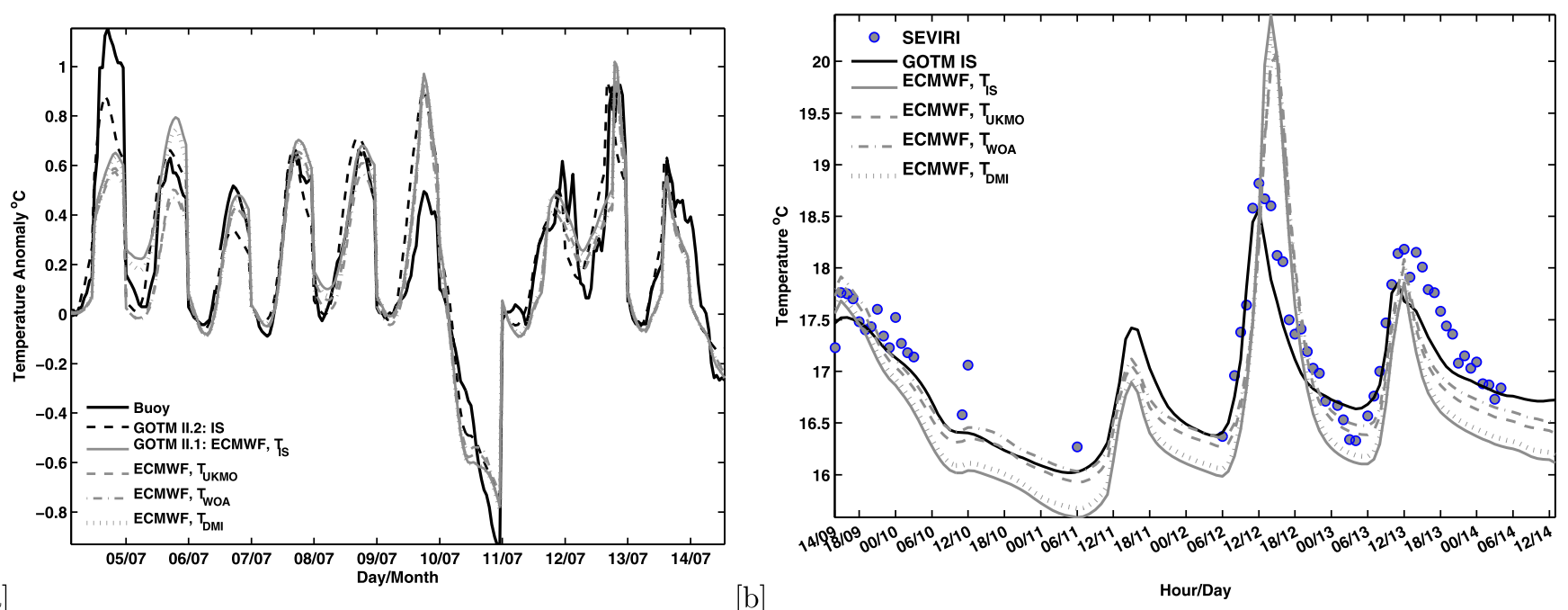

$[\mathrm{a}]$

$[\mathrm{b}]$

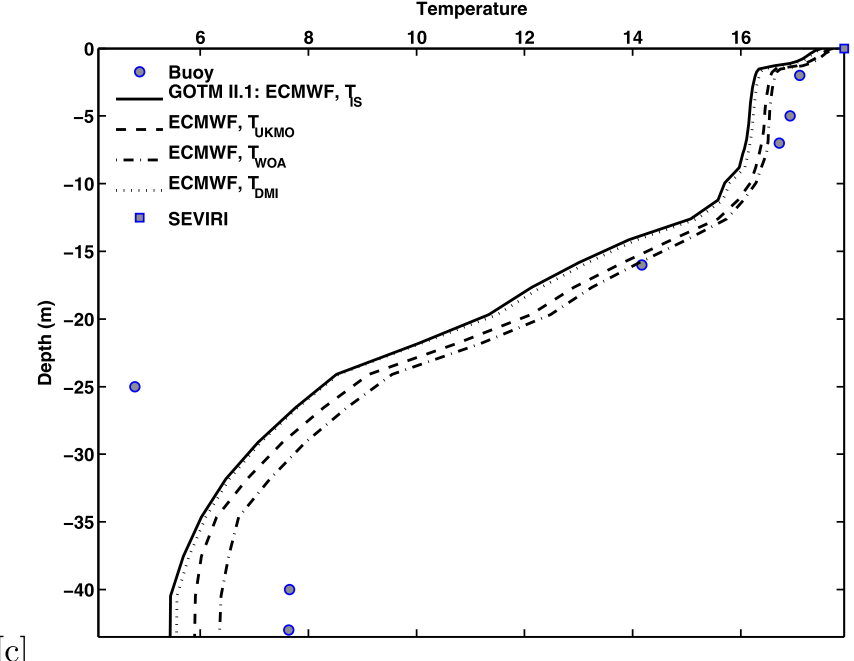

Figure 6. (a) $2 \mathrm{~m}$ depth diurnal variability at the Arkona Becken buoy (black solid) and from GOTM using in situ (black dashed) or ECMWF forcing fields and different temperature profiles (gray), 4-14 July 2013. (b) GOTM top layer temperature (solid), with in situ (black) or ECMWF (gray) forcing fields with options III.1 and VI.7, and SEVIRI (circles) subskin SST, 9-14 July 2013. (c) Vertical temperature from the measurements (circles), GOTM with ECMWF forcing fields (lines) and SEVIRI on 13 July 2013, 13:00.

been found to occur. A successful model of the upper ocean temperature can be implemented in ocean models that typically do not resolve the upper layers. In addition, as the amount and accuracy of satellite SST fields increases, modeling of the diurnal signal is fundamental to achieve an improved blending of retrievals and generate higher quality blended SST products. For many biological processes, e.g. coral bleaching, an accurate SST including the diurnal signal is required to better monitor and understand the relevant processes. This study proposes a modeling approach for SST that can aid various applications that require systematic monitoring of the diurnal variability.

GOTM includes a series of parameterizations to describe the simulated physical processes. Thus, examining the sensitivity of the produced results to the model setup is fundamental. Focus was given on the surface heat budget which is important for diurnal warming. Analyses not presented here resulted in significant deviations from the observed temperature when directly prescribing the surface fluxes. Pimentel et al. [2008a] also found that calculating the surface fluxes using ECMWF forcing fields yielded better results than directly prescribing them, which was attributed to the skin parameterization used by the Fairall et al. [1996b] algorithm implemented in GOTM. From existing results and given that surface heat and momentum fluxes are not measured in situ justify the rationale behind using surface meteorological variables to calculate the heat budget. 
Internal calculation of the short-wave radiation in GOTM uses the time, location and cloud cover information; the latter being used for the albedo estimation. Due to lack of cloud cover information calculating the short-wave radiation was less accurate than prescribing it. In cases where the short-wave radiation was calculated from in situ measurements, the cloud cover field was set to zero resulting in higher calculated values and higher modeled temperature. Using the ECMWF short-wave radiation field yielded better results than calculating it using the NWP cloud cover field, possibly associated with the higher uncertainty of latter. The ECMWF prescribed short-wave radiation reflects the net amount at the surface while in situ measurements reflect only the incoming part, which still includes the albedo reflected part and is thus higher. This justifies the disagreement shown at the bottom plots of Figure 4 (first column), where the buoy short-wave radiation is higher than ECMWF. It may also partly explain the higher bias between GOTM and the buoy temperature at Arkona Becken (Table 2) when the short-wave radiation is directly prescribed compared to when being calculated from measurements, despite that cloud cover is not available and even the calculation is not accurate.

The better performance of the ECMWF prescribed short-wave radiation compared to the calculated one was consistent for the PIRATA and Arkona Becken cases, since the measured and ECMWF short-wave radiation agreed relatively well at both locations. All other meteorological variables were also in good agreement at Arkona Becken, but that was not the case at the PIRATA buoy. Despite the deviations of the ECMWF forcing fields from the in situ measurements (Figure 4), the GOTM-Buoy RMS errors in Table 3 are the same at PIRATA and $0.05^{\circ} \mathrm{C}$ larger at MLML91, when ECMWF is used instead of the in situ forcing. Increased RMS errors at MLML91 occur for initial temperature profiles other than the in situ measured.

Large diurnal warming events are often observed after days with smaller diurnal warming events (see Figure $5 b$ ). The influence of the upper ocean preconditioning related to events of previous days was tested for the PIRATA case (Figure 5). GOTM was initialized the day of the large event and the modeling period was shortened from 4 to 2 days while all other settings remained the same, i.e. runs using the in situ and ECMWF forcing fields were performed and the climatological profiles were also used. Using the in situ forcing resulted in no change while a slight decrease, generally $<0.15^{\circ} \mathrm{C}$, of modeled temperature accompanied by a minor increase in $\mu, \sigma$, and RMSE of $\sim 0.05^{\circ} \mathrm{C}$ occurred when using ECMWF forcing.

The light extinction parameterization controls the absorption of downward radiation in the water column, with an impact previously demonstrated by Simpson and Dickey [1981]. Shinoda [2005] showed the sensitivity of the diurnal SST cycle's amplitude to the solar radiation penetrating the sea surface; Jerlov II type water resulted in larger amplitudes compared to Jerlov I, IA, and IB in the western Equatorial Pacific. Our findings at the three locations in the Atlantic and Baltic Sea are similar for the 2-band model. The 9-band model resulted in larger amplitudes when using both the attenuation lengths and proportional coefficients from Paulson and Simpson [1981]; a gradual decrease occurred when proportional coefficients from MODTRAN and COART were used, correspondingly. The COART $34.8 \mathrm{~m}$ depth coefficient is twice as large as that from Paulson and Simpson [1981] which results to more light penetrating at greater depths, also demonstrated in the profiles shown in Figure $5 \mathrm{c}$. The black and gray solid lines were produced using the Paulson and Simpson [1981] values which resulted in higher temperatures in the upper $20 \mathrm{~m}$ and lower at $40 \mathrm{~m}$. The gray dashed and dotted lines were produced using the COART model coefficients, and clearly show higher temperature at the depth of $40 \mathrm{~m}$, matching the buoy, and slightly lower temperature from 1 to $10 \mathrm{~m}$ as a result of less heat being absorbed there.

Pimentel et al. [2008a] used the 2-equation parameterization of Ohlmann and Siegel [2000] for the light extinction, based on the chlorophyll concentration, cloud cover, and solar zenith angle which was proven to accurately resolve variations in the solar transmission occurring in the top few meters of the water column. Water opacity has been found to correlate well with warming [Merchant et al., 2008] but chlorophyll concentration alone may not hold a major role in the heat uptake from the infrared part of the spectrum as it does not absorb at this band. Nonetheless, chlorophyll concentration could be considered as a proxy of the light extinction coefficient in the ocean since Pimentel et al. [2008a] found a slight reduction in the root mean square errors when using the proposed parameterization of Ohlmann and Siegel [2000] instead of the 9-band model with coefficients from Paulson and Simpson [1981]. Our study has also demonstrated some reduction of $\sigma$ when using the 9-band model with coefficients from MODTRAN and COART compared to those of Paulson and Simpson [1981]. 
The 9-band light extinction model consistently showed good comparisons with the in situ temperatures. Differences in $\sigma$ did not exceed $0.1^{\circ} \mathrm{C}$ for the various options but $\mu$ exceeded $0.5^{\circ} \mathrm{C}$ while instantaneous differences at the peak of diurnal warming reached up to $0.8^{\circ} \mathrm{C}$. Modulation of the light absorption is a contributing factor to the regional differences of the diurnal cycle characteristics reported in Karagali and Høyer [2014]. While no universal parameterization can be selected, the 9-band model appears as more appropriate at large spatial scales. A light extinction model accounting for water turbidity may have a more general applicability and it should, ideally, not rely only on chlorophyll concentrations. In conclusion, the effect of the spatial variations of the light extinction coefficient could be taken into consideration in future developments of the radiative transfer modeling efforts.

NWP forcing fields and climatological or modeled temperature profiles need to be used when diurnal variability estimates over large areas are of interest, since measurements are limited in space and time. In this study, it was demonstrated that 3 hourly ECMWF forcing parameters can effectively reproduce the diurnal signal of upper ocean heating, at the tested locations, and resulted in GOTM minus buoy temperature $\sigma$ values similar to the ones produced when in situ measurements were used. Radiative fluxes from satellite observation are becoming available, e.g. from EUMETSAT through the O\&SI-SAF, and they could be used to test the model performance.

Hourly updating the initial temperature profile did not result in any significant change of the modeled temperature, compared to using only one profile at the beginning of the simulation, at least for simulated intervals of up to 4 days. Figure $5 \mathrm{~b}$ shows that 2 days after initialization, GOTM $2 \mathrm{~m}$ temperatures well matched the observations at various depths. An impact of the type of temperature profile was identified, with the WOA profile producing better statistics at the PIRATA and Arkona Becken locations.

Pimentel et al. [2008a] reported root mean square errors ranging from 0.13 to $0.21^{\circ} \mathrm{C}$ depending on the time resolution of the forcing fields and the location, similar to statistics reported here; RMSE values ranging between 0.10 and $0.20^{\circ} \mathrm{C}$ for the MLML91 and PIRATA stations, and using in situ temperature profiles. For Arkona Becken, RMSE values ranged from 0.16 to $0.24^{\circ} \mathrm{C}$ using ECMWF forcing fields and climatological temperature profiles. Comparisons between GOTM and SEVIRI for a 5 day interval at the Arkona Becken site, also showed similar RMS errors when the in situ forcing fields were used. It is speculated that some of the larger RMSE values found in the present study, especially between SEVIRI and GOTM, are due to the use of a different light extinction scheme and the exclusion of the North Sea/Baltic Sea region in the study of Pimentel et al. [2008a].

This study has demonstrated that GOTM is a good candidate model for diurnal SST variability. Using the first order $\mathrm{K} \epsilon$ turbulence scheme, the dynamic dissipation length scale method and the Kantha and Clayson [1994] quasiequilibrium version for the stability method, showed consistently good results compared to the in situ measurements. The generic length scale method produced similar statistical results as well. Three hourly ECMWF forcing fields were adequate for reproducing temperatures observed from in situ and satellite sensors, at the tested locations. A range of sensitivity tests indicated that it is advised to use the NWP short-wave radiation field if available, than calculate it using the cloud cover field. A 9-band model for the light extinction resulted in consistently good statistics independent of the location, with coefficients from MODTRAN and COART. Such recommendations of a generic setup can be implemented to run GOTM in large domains and for longer time scales. RMSE as low as $0.2^{\circ} \mathrm{C}$ and correlation up to 0.97 between modeled and in situ temperatures and 0.94 between modeled and satellite-derived SSTs are reported.

Acknowledgments

This study is part of the SSTDV: R.EX.IM.A.M. project supported by the European Space Agency (ESA) Support to Science Element (STSE) 2012. The WHOI UOP Group and Nan Galbraith (http://uop.whoi.edu/archives/ dataarchives.html), the TAO Project Office of NOAA/PMEL for PIRATA, the BSH Institute and MARNET network for Arkona Becken, O\&SI-SAF, the MyOcean project, NODC, and the UKMO Hadley Centre. GOTM functions were based on the work of Hallsworth [2005].

\section{References}

Berliand, M. E., and T. G. Berliand (1952), Measurement of the effective radiation of the earth with consideration of the effect of cloudiness (in Russian), Izv. Akad. Nauk SSSR, Ser. Fiz., 1, 1952.

Bernie, D. J., S. J. Woolnough, and J. M. Slingo (2005), Modeling diurnal and intraseasonal variability of the ocean mixed layer, J. Clim., 18, 1190-1202.

Bernie, D. J., E. Guilyardi, G. Madec, J. M. Slingo, and S. J. Woolnough (2007), Impact of resolving the diurnal cycle in an ocean-atmosphere GCM. Part 1: A diurnally forced OGCM, Clim. Dyn., 29, 575-590.

Bernie, D. J., E. Guilyardi, G. Madec, J. M. Slingo, S. J. Woolnough, and J. Cole (2008), Impact of resolving the diurnal cycle in an oceanatmosphere GCM: Part 2: A diurnally coupled CGCM, Clim. Dyn., 31, 909-925.

Bignami, F., S. Marullo, R. Santoleri, and M. E. Schiano (1995), Longwave radiation budget in the Mediterranean Sea, J. Geophys. Res., 100, 2501-2514.

Burchard, H., and H. Baumert (1995), On the performance of a mixed-layer model based on the k-epsilon turbulence closure, J. Geophys. Res., 100, 8523-8540. 
Burchard, H., K. Bolding, and M. R. Villarreal (1999), GOTM-A general ocean turbulence model. Theory, applications and test cases, Tech. Rep. EUR 18745 EN, Eur. Comm. Brussels, Belgium.

Clark, N. E., L. Eber, R. M. Laurs, J. A. Renner, and J. F. T. Saur (1974), Heat exchange between ocean and atmosphere in the Eastern North Pacific for 1961-1971, Tech. Rep. NMFS SSRF-682, NOAA, U.S. Dept. of Commer., Washington, D. C.

Clayson, C. A., and A. S. Bogdanoff (2013), The effect of diurnal sea surface temperature warming on climatological air-sea fluxes, J. Clim., $26,2546-2556$

Clayson, C. A., and D. Weitlich (2007), Variability of tropical diurnal sea surface temperature, J. Clim., 20(2), 334-352.

Donlon, C. J., et al. (2010), Successes and challenges for the modern sea surface temperature observing system, in Proceedings of OceanObs09: Sustained Ocean Observations and Information for Society, 2, Venice, Italy, 21-25 September 2009, edited by J. Hall, D. E. Harrison, and D. Stammer, ESA Publ. WPP-306, doi:10.5270/OceanObs09.cwp.24.

Embury, O., C. J. Merchant, and G. K. Corlett (2012), A reprocessing for climate of sea surface temperature from the along-track scanning radiometers: Initial validation, accounting for skin and diurnal variability effects, Remote Sens. Environ., 116, 62-78.

Fairall, C. W., E. F. Bradley, J. S. Godfrey, G. A. Wick, J. B. Edson, and G. S. Young (1996a), Cool-skin and warm-layer effects on sea surface temperature, J. Geophys. Res., 101, 1295-1308.

Fairall, C. W., E. F. Bradley, D. P. Rogers, J. B. Edson, and G. S. Young (1996b), Bulk parameterization of air-sea fluxes for TOGA-COARE, J. Geophys. Res., 101, 3747-3764.

Filipiak, M. J., C. J. Merchant, H. Kettle, and P. Le Borgne (2012), An empirical model for the statistics of sea surface diurnal warming, Ocean Sci., 8(2), 197-209.

Gentemann, C. L., C. J. Donlon, A. Stuart-Menteth, and F. J. Wentz (2003), Diurnal signals in satellite sea surface temperature measurements, Geophys. Res. Lett., 30(3), 1140, doi:10.1029/2002GL016291.

Gentemann, C. L., P. J. Minnett, and B. Ward (2009), Profiles of Ocean Surface Heating (POSH): A new model of upper ocean diurnal warming, J. Geophys. Res., 114, C07017, doi:10.1029/2008JC004825.

Good, S. A., M. J. Martin, and N. A. Rayner (2013), EN4: Quality controlled ocean temperature and salinity profiles and monthly objective analyses with uncertainty estimates, J. Geophys. Res. Oceans, 118, 6704-6716, doi:10.1002/2013JC009067.

Grant, A. L. M., and P. Hignett (1998), Aircraft observations of the surface energy balance in TOGA-COARE, Q. J. R. Meteorol. Soc., 124, $101-122$.

Hallsworth, S. (2005), Modelling the diurnal variation of sea surface temperature using a one-dimensional ocean turbulence model, PhD Thesis, Univ. of Edinburgh, Scotland.

Hastenrath, S., and P. J. Lamb (1978), Heat Budget Atlas of the Tropical Atlantic and Eastern Pacific Oceans, 103 pp., Univ. of Wisconsin, Madison.

Jerlov, N. G. (1968), Optical Oceanography, 194 pp., Elsevier, New York.

Jin, Z., T. P. Charlock, K. Rutledge, K. Stamnes, and Y. Wang (2006), Analytical solution of radiative transfer in the coupled atmosphereocean system with a rough surface, Appl. Opt., 45, 7443-7455.

Kantha, L. H., and C. A. Clayson (1994), An improved mixed layer model for geophysical applications, J. Geophys. Res., 99, 25,235-25,266.

Karagali, I., and J. L. Høyer (2013), Observations and modelling of the diurnal SST cycle in the North and Baltic Seas, J. Geophys. Res. Oceans, 118, 4488-4503, doi:10.1002/jgrc.20320.

Karagali, I., and J. L. Høyer (2014), Characterisation and quantification of regional diurnal SST cycles from SEVIRI, Ocean Sci., 10, 745-758.

Karagali, I., J. L. Høyer, and C. B. Hasager (2012), SST diurnal variability in the North Sea and the Baltic Sea, Remote Sens. Environ., 121, $159-170$.

Locarnini, R. A., et al. (2013), World Ocean Atlas 2013, Volume 1: Temperature, edited by S. Levitus and A. Mishonov, NOAA Atlas NESDIS 73 , 40 pp. Natl. Oceanogr. Data Cent., U.S. Dep. of Comm., Silver Spring, Md.

Marullo, S., P. J. Minnett, R. Santoleri, and M. Tonani (2016), The diurnal cycle of sea-surface temperature and estimation of the heat budget of the Mediterranean Sea, J. Geophys. Res. Oceans, 121, 8351-8367, doi:10.1002/2016JC012192.

Merchant, C. J., O. Embury, J. Roberts-Jones, E. Fiedler, C. E. Bulgin, G. K. Corlett, S. Good, A. McLaren, N. Rayner, S. Morak-Bozzo, and C. Donlon (2014), Sea surface temperature datasets for climate applications from Phase 1 of the European Space Agency Climate Change Initiative (SST CCI), Geosci. Data J., 1, 179-191.

Merchant, C. J., M. J. Filipiak, P. Le Borgne, H. Roquet, E. Autret, J.-F. Piollé, and S. Lavender (2008), Diurnal warm-layer events in the western Mediterranean and European shelf seas, Geophys. Res. Lett., 35, L04601, doi:10.1029/2007GL033071.

Ohlmann, J. C., and D. A. Siegel (2000), Ocean radiant heating. Part II: Parameterizing solar radiation transmission through the upper ocean, J. Phys. Oceanogr., 30, 1849-1865.

Ocean \& Sea Ice SAF (2013), Geostationary Sea Surface Temperature (Products OSI-206, 207) Product User Manual, Météo-France, Version 1.3, EUMETSAT, Darmstadt, Germany.

Paulson, C. A., and J. J. Simpson (1981), The temperature difference across the cool skin of the ocean, J. Geophys. Res., 86, 11,044-11,054.

Pimentel, S. (2007), Estimation of the diurnal variability of sea surface temperatures using numerical modelling and the assimilation of satellite observations, PhD Thesis, Univ. of Reading, Reading, U. K.

Pimentel, S., K. Haines, and N. K. Nichols (2008a), Modeling the diurnal variability of sea surface temperatures, J. Geophys. Res., 113, C11004, doi:10.1029/2007JC004607.

Pimentel, S., K. Haines, and N. K. Nichols (2008b), The assimilation of satellite-derived sea surface temperatures into a diurnal cycle model, J. Geophys. Res., 113, C09013, doi:10.1029/2007JC004608.

Plueddemann, A. J., R. A. Weller, M. Stramska, T. D. Dickey, and J. Marra (1995), The vertical structure of the upper ocean during the Marine Light-Mixed Layer experiment, J. Geophys. Res., 100, 6605-6619.

Price, J. F., R. A. Weller, and R. Pinkel (1986), Diurnal cycling: Observations and models of the upper ocean response to diurnal heating, cooling and wind mixing, J. Geophys. Res., 91, 8411-8427.

Schiller, A., and J. S. Godfrey (2005), A diagnostic model of the diurnal cycle of sea surface temperature for use in coupled oceanatmosphere models, J. Geophys. Res., 110, C11014, doi:10.1029/2005JC002975.

Sellschopp, J., L. Arneborg, M. Knoll, V. Fiekas, F. Gerdes, H. Burchard, H. U. Lass, V. Mohrholz, and L. Umlauf (2006), Direct observations of a medium-intensity inflow into the Baltic Sea, Cont. Shelf Res., 26(19), 2393-2414.

Shinoda, T. (2005), Impact of the diurnal cycle of solar radiation on intraseasonal SST variability in the western Equatorial Pacific, J. Clim., 18(14), 2628-2636.

Simpson, J. J., and T. D. Dickey (1981), The relationship between downward irradiance and upper ocean structure, J. Phys. Oceanogr., 11(3), 309-323.

Stuart-Menteth, A. C., I. S. Robinson, and C. J. Donlon (2005), Sensitivity of the diurnal warm layer to meteorological fluctuations: Part 2: A new parameterization for diurnal warming, J. Atmos. Ocean Sci., 10(1-4), 209-234. 
Takaya, Y., J.-R. Bidlot, A. C. M. Beljaars, and P. A. E. M. Janssen (2010), Refinements to a prognostic scheme of skin sea surface temperature, J. Geophys. Res., 115, C06009, doi:10.1029/2009JC005985.

Umlauf, L., and H. Burchard (2003), A generic length scale equation for geophysical turbulence models, J. Mar. Res., 61, $235-265$.

Ward, B. (2006), Near-surface ocean temperature, J. Geophys. Res., 111, C02005, doi:10.1029/2004JC002689.

Webster, P. J., C. A. Clayson, and J. A. Curry (1996), Clouds, radiation, and the diurnal cycle of sea surface temperature in the Tropical Western Pacific, J. Clim., 9, 1712-1730.

Zeng, X., and E. Dickinson (1998), Impact of the diurnally-varying skin temperature on surface fluxes over the tropical Pacific, Geophys. Res. Lett., 25, 1411-1414.

Zeng, X., and A. Beljaars (2005), A prognostic scheme of sea surface skin temperature for modeling and data assimilation, Geophys. Res. Lett., 32, L14605, doi:10.1029/2005GL023030. 